\section{Immunoglobulin $\mathrm{G}$ (IgG), IgG1, and IgG2 determinations from endoscopic biopsy specimens in control, Crohn's disease, and ulcerative colitis subjects}

\author{
J Rüthlein, M Ibe, W Burghardt, J Mössner, I O Auer
}

are increased in inflamed lamina propria of ulcerative colitis and Crohn's disease patients. With isolated cells, it was also shown that membrane IgG positive membrane cells were increased, ${ }^{6}$ but in two studies ${ }^{7}$ in which patients with inflammatory bowel disease in remission were investigated, the number of IgG immunocytes in the mucosa was marginally or not increased. However, IgG synthesis is not merely dependent on the number of plasma cells, but also on the functional state of these cells and factors which control this function. Lamina propria mononuclear cells (LPMC) of macroscopically unaffected mucosa obtained by surgery still produced more IgG than those of normal controls. ${ }^{9}$ The latter finding favours the hypothesis that IgG immunocyte infiltration of the mucosa and IgG production are early events in the inflammatory cascade in ulcerative colitis and Crohn's disease mucosa.

The first aim of our study was to obtain intestinal mononuclear cells (IMNC) from all clinical and histological stages of inflammatory bowel disease, including remission, to measure IgG and IgG subclass production of these cells in vitro, and to compare both disease groups with normal subjects and non-inflammatory bowel disease control subjects with unspecific colitis. To achieve this goal it was essential to establish a technique to isolate enough IMNC from endoscopic biopsy specimens.

Severely inflamed mucosa of ulcerative colitis and Crohn's disease patients shows a different IgG subclass distribution on histological examination. ${ }^{10}$ In LPMC obtained by surgical specimen from ulcerative colitis patients the increase in total IgG produced is predominantly IgG1. ${ }^{11}$ However, in functional studies signficant differences in the proportion of IgG subclasses have not been shown. The second aim of the study was to investigate whether there was a significant change in IgG subclass ratios in patients with inflammatory bowel diseases compared with control subjects and how it was related to the degree of inflammation.

\section{Methods}

\section{PATIENTS}

Seventy eight patients were recruited from the endoscopy units of Medizinische Universitätsklinik Würzburg, Medizinische UniversitätsPoliklinik Würzburg, and the Medical Department at the Juliusspital in Würzburg. Patients were not endoscopied for the purposes of this aetiology and pathogenesis of ulcerative colitis and Crohn's disease are still unknown, yet several phenomena make it likely that a disturbance of the mucosal immune system plays an important role in both. In this respect immunohistochemical examination has shown that cytoplasmic immunoglobulin $\mathrm{G}(\mathrm{IgG})^{1-5}$ positive cells 
study. All patients consented to undergo biopsy for this study and the investigation was approved by the ethical committee of the university.

Nineteen patients were referred for endoscopy with a preliminary diagnosis of ulcerative colitis and 29 patients with Crohn's disease. Fifteen samples were excluded from this study because of reasons stated in the results section. All patients underwent total endoscopy and had biopsy specimens taken from the ascending colon or the most proximal part of large bowel if they had a right sided colectomy.

All patients were evaluated using a simplified index of Crohn's disease ${ }^{1213}$ or a modified form for ulcerative colitis, ${ }^{14-16}$ consisting of clinical and subjective variables only. All patients had blood examination of acute phase proteins and erythrocyte sedimentation rate (ESR) (Westergren method). Systemic inflammation ${ }^{17}$ was assumed if at least two inflammation indicators were in the abnormal range (ESR above $30 \mathrm{~mm} / 1 \mathrm{st}$ hour, $\mathrm{C}$ reactive protein above $15 \mathrm{mg} / \mathrm{l}$, orosomucoid above $1400 \mathrm{mg} / \mathrm{l})$. Only patients with no abnormal acute phase parameters were classified as being without systemic inflammation. Macroscopic and histological grading of the colon was done according to Gomes $e \mathrm{al}^{14}$ by addition of six grading areas from caecum to rectum. The colon was graded $0-3$ macroscopically $(0=$ normal, $3=$ severe disease with ulcers and spontaneous bleeding) and $0-4(0=$ normal, 3 and $4=$ destructive crypt abscess and ulceration) histologically at each area.

\section{INTESTINAL CELL ISOLATION}

Six to eight biopsy specimens used for cell isolation were immediately transferred into cold RPMI-1640 medium (Biochrom, Berlin, Germany). Single cells were obtained by a modified enzymatic technique. ${ }^{6}$ The specimens were washed several times in $\mathrm{Ca} / \mathrm{Mg}$ free $\mathrm{PBS}$ (GIBCO, Berlin, Germany) and then incubated at $4^{\circ} \mathrm{C}$ overnight in culture medium (RPMI 1640 medium with $10 \%$ fetal calf serum (GIBCO), antibiotics (GIBCO), and fungizone (GIBCO)), containing collagenase CLSPA (Biochrom) and hyaluronidase (Sigma, Deisenhofen, Germany). The next day the cell suspension was incubated at $37^{\circ} \mathrm{C}$ for 60 minutes with constant stirring to release mononuclear cells. The digested specimens were passed through steel meshes with a pore size of 500 and $300 \mu \mathrm{m}$. After thorough washing, the cells were put on a discontinuous Percoll density gradient with $70 \%$ Percoll, $30 \%$ Percoll and culture medium and centrifuged. IMNC could be harvested from the $70 \% / 30 \%$ Percoll interface.

IMNC viability was $>85 \%$, as determined by trypan blue exclusion. In several experiments flow cytometry was performed with an aliquot of cells using anti-CD20 (clone L27), anti-CD3 (clone SK7) (Becton-Dickinson, Heidelberg, Germany) and anti-CD22 (clone To15) (Dako, Hamburg, Germany) using a protocol supplied by the companies. Some 400000 IMNC were seeded into each well of a 96 well microtitre plate and supplemented with $250 \mu \mathrm{l}$ of culture medium. No stimulants were added. The cell culture was incubated at $37^{\circ} \mathrm{C}$ in a humidified atmosphere with $5 \% \mathrm{CO}_{2}$ for 14 days. Supernatants of the cultured cells were collected after centrifugation at $1000 \mathrm{~g}$ for five minutes and stored at $-20^{\circ} \mathrm{C}$ until used for analysis.

ELISA TO MEASURE IgG, IgGl AND IgG2

IgG in the culture supernatants was determined by an ELISA with 96 well flat-bottomed microtitre plates as described previously. ${ }^{18}$ For IgGl determinations we replaced the coating antibody by a monoclonal anti-IgGl (clone SG16 as processed ascites fluid) (Biomakor, Renner, Dannstadt, Germany). The optical densities were measured by a photometer (SLT-easy reader, Gröding, Austria) and the sample IgGl concentration was calculated from IgGl standards (Sigma) by double logarithmic regression.

To assess the cross reactivity of our ELISA procedures, we used a subclass standard (primary standard WHO reference serum 67/97) (Nordic, Bochum, Germany), which contained known quantities of all IgG subclasses. IgG and IgG1 subclass determinations with our procedure reproduced the concentration of this sample $(+/-10 \%)$. Double determination of IgG and IgGI subclass with a commercial IgG subclass assay (Binding Site, Birmingham, UK) and our assay showed less than $7 \%$ deviation between each other.

IgG2 determinations were done with a commercial assay (Binding Site, Birmingham, UK) using a similar protocol, that was supplied with the ELISA test. According to the supplier, the specificity of the antibodies used in this assay were determined in a WHO/IUIS collaborative study. ${ }^{19}$

\section{STATISTICAL EVALUATION}

As IgG and IgGl data in all groups were not normally distributed we used centiles in all Tables and Figures; median ( $=50$ th centile), 90th, and 10 th centile are shown. Non-parametric statistical tests were used as indicated (Wilcoxon U test and Spearman signed rank test).

\section{Results}

We isolated IMNC from 78 patients. In this study, 29 patients with Crohn's disease, 19 patients with ulcerative colitis, three patients with unspecific colitis, and 12 patients without gastrointestinal disease were evaluated. Patients with inflammation of the ileum (Crohn's disease of the ileum or backwash ileitis in ulcerative colitis) were included in this study, but ileal inflammation was not counted in the disease scores. There were no patients with inflammation of the ileum only.

\section{ISOLATION OF IMNC FROM BIOPSY SPECIMENS}

With enzymatic digestion and density gradients we were able to isolate viable IMNC from specimens that were used for functional studies. With this technique we could obtain between 500000 and 5 million cells from 6 to 8 specimens. Viability was always $>85 \%$. The cell number was dependent on the size of the specimens and 
TABLE I Immunoglobulin $G(I g G)$ and IgGI production in the different groups of subjects

\begin{tabular}{|c|c|c|c|c|c|c|c|}
\hline & \multirow[b]{2}{*}{ No } & \multicolumn{3}{|c|}{ Immunoglobulin $G$} & \multicolumn{3}{|c|}{ Immunoglobulin $G I$} \\
\hline & & $10 \%$ & Median & $90 \%$ & $10 \%$ & Median & $90 \%$ \\
\hline Controls & 12 & 30 & 46 & 101 & 12 & 24 & 65 \\
\hline Crohn's disease & 29 & 56 & $114^{\star}$ & 373 & 13 & $48^{\star}$ & 243 \\
\hline Ulcerative colitis & 19 & 30 & $139^{\star}$ & 521 & 13 & $125^{\star}$ & 391 \\
\hline Unspecific colitis & 3 & 35 & 86 & 100 & 11 & 20 & 80 \\
\hline
\end{tabular}

${ }^{\star} \mathrm{p}<0 \cdot 05$ compared with controls using Wilcoxon $U$ test.

TABLE II Wilcoxon $U$ test to determine significance of changes in immunoglobulin $G(I g G)$ and IgGI production between Crohn's disease or ulcerative colitis patients with and without acute phase reactions in blood examinations

\begin{tabular}{|c|c|c|c|}
\hline & \multirow[b]{2}{*}{ No } & \multicolumn{2}{|c|}{ Median $(n g / m l)$} \\
\hline & & $I g G$ & $I g G I$ \\
\hline $\begin{array}{l}\text { CD with SIR } \\
\text { CD without SIR }\end{array}$ & $\begin{array}{r}12 \\
9\end{array}$ & $\left.\begin{array}{r}118 \\
86\end{array}\right\} \mathrm{NS}$ & $\left.\begin{array}{r}110 \\
40\end{array}\right\} \mathrm{NS}$ \\
\hline $\begin{array}{l}\text { UC with SIR } \\
\text { UC without SIR }\end{array}$ & $\begin{array}{r}10 \\
5\end{array}$ & $\left.\begin{array}{r}143 \\
80\end{array}\right\} *$ & $\left.\begin{array}{r}151 \\
30\end{array}\right\} \star$ \\
\hline
\end{tabular}

SIR = systemic inflammatory reaction .

the degree of inflammation. Phenotyping of IMNC in several experiments showed that 6-26\% were CD20 positive, $5-27 \%$ were CD22 positive, and $45-88 \%$ were $C D 3$ positive cells.

IgG AND IgGl PRODUCTION IN THE FOUR GROUPS In all Tables and Figures median and $10 \%$ and $90 \%$ centiles are shown. The IgG and IgGl production in vitro for the different disease groups is shown in Table I. The IgG and IgGl production of patients with Crohn's disease or ulcerative colitis was significantly raised in comparison with controls (Wilcoxon U test). In mild unspecific colitis we found increased IgG and normal IgGl. Because of the small sample number we could not test unspecific colitis patients against other groups.

(It) mononuclear cells intestinal mono from patients with ulcerative colitis and Crohn's disease. Patients are subdivided according to the macroscopic appearance of the mucosa with a Gomes's score $(><5$ $\square)$ and with a local score $(><2, \mathbb{N})$ at the site from which the biopsies were taken.

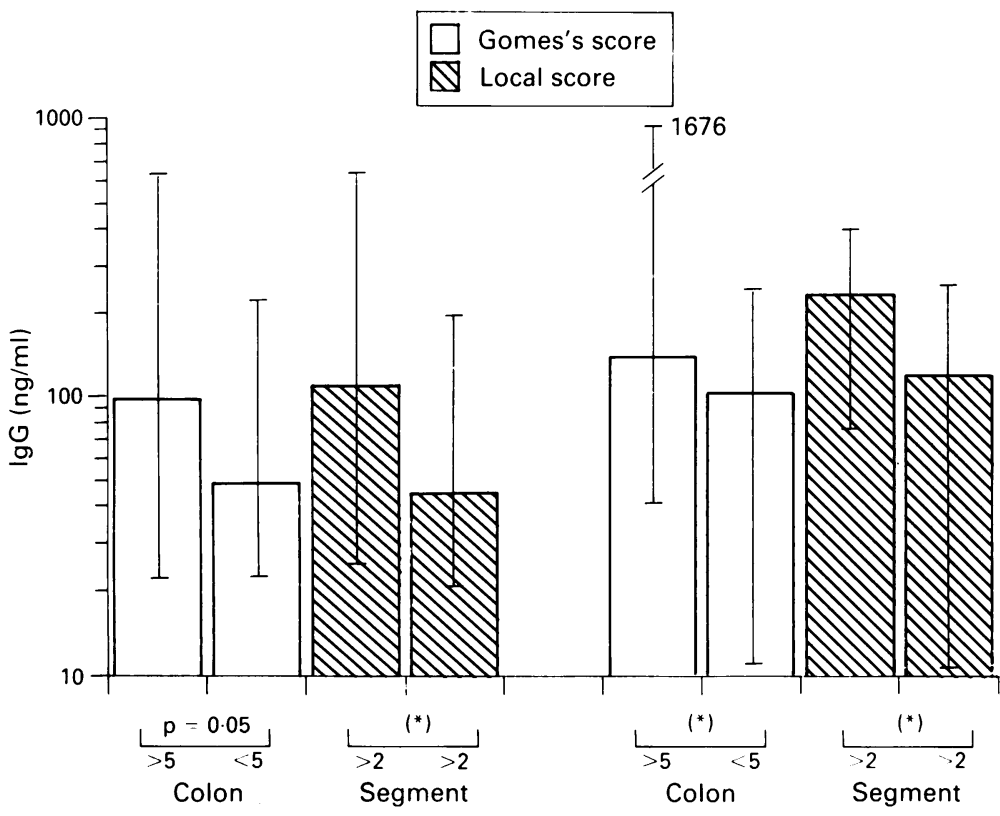

Crohn's disease
IgG AND IgGI IN RELATION TO CLINICAL INDICES OF DISEASE ACTIVITY

When Crohn's disease and ulcerative colitis

patients were separated into subgroups of patients with and without systemic inflammation we could show increased IgG and IgGl in supernatants of those with systemic inflammation, yet this only reached significance in ulcerative colitis patients (Table II). There was no significant correlation between IgG or IgGl production and clinical activity scores such as the simplified CDAI or the similar index for ulcerative colitis (UCAI according to Gomes et al modified from Truelove and Witts) (data not shown).

IgG AND IgGl PRODUCTION IS DEPENDENT ON ENDOSCOPIC DISEASE SEVERITY ASSESSED BY THE GOMES'S INDEX IN CROHN'S DISEASE AND ULCERATIVE COLITIS

As IgG and IgGl production in vitro is probably influenced by the degree of inflammation we subsequently grouped the patients with Crohn's disease and ulcerative colitis according to the grade of macroscopic inflammation. Using the endoscopic score devised by Gomes ${ }^{7}$ for the entire colon (Fig 1, open bars), we found significant differences in IgGl production according to the degree of inflammation (Gomes's score $>$ or $<5)$ in Crohn's disease and ulcerative colitis patients. Similar results for IgG are not shown.

Finally we used the macroscopic appearance of the mucosa at the site from which the biopsy specimen was taken to classify Crohn's disease and ulcerative colitis patients into two groups. To emphasise the difference between inflammatory stages we have grouped patients with Gomes grade $<2$ and Gomes's grade $>2$ and have omitted patients with intermediate inflammation. We found significant differences in IgG1 concentrations between severely inflamed and slightly inflamed specimens in both diseases (Fig 1, hatched bars). Similar data were obtained when total IgG production was compared.

\section{IgG AND IgGl PRODUCTION IN RELATION TO}

HISTOLOGICAL INFLAMMATION OF THE MUCOSA When Crohn's disease and ulcerative colitis patients were grouped according to histological criteria devised by Gomes into severely and mildly inflamed cases (Gomes's score < or $>9$ ), we found a tendency to higher IgG and IgGl production in the subgroup with severe inflammation. In spite of this trend the difference did not reach significance in either disease (IgG production not shown, IgGl production shown in Fig 2, open bars). However, when local inflammation in the colonic segment was compared with the IgG and IgGl production in the same segment, we found a significant difference in ulcerative colitis patients (Fig 2 hatched bars).

IgG AND IgGI PRODUCTION OF IMNC IN ULCERATIVE COLITIS AND CROHN'S DISEASE PATIENTS WITH SLIGHT INFLAMMATION OF THE MUCOSA

To examine if IgG and $\operatorname{IgG} 1$ production is an early event in the inflammatory reaction of the mucosa, we compared local IgG and IgGl production of Crohn's disease and ulcerative colitis 


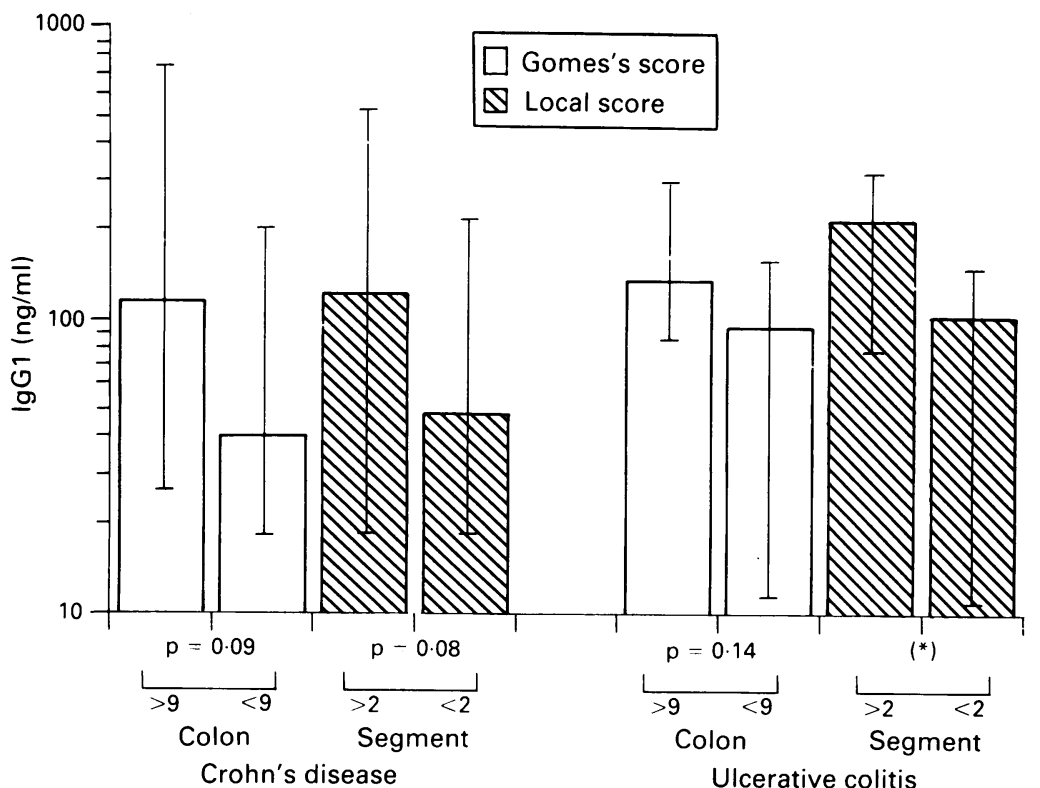

Figure 2: Immunoglobulin GI (IgGI) production of intestinal mononuclear cells from patients with ulcerative colitis and Crohn's disease. Patients are subdivided according to the histological Gomes's score $><9, \square$ ) and according to a local score $(><2, \mathbb{N})$ at the site from which the biopsies were taken.

Figure 3: Ratio (SEM) of in vitro production of immunoglobulin GI (IgGI) and IgG. Ratios for controls, Crohn's disease, and ulcerative colitis, as well as subgroups of the diseases are shown (according to the macroscopic and histological score at the biopsy site). Severe inflammation is indicated by 自 and mild inflammation by $\mathbb{Z}$ $\star p<0.05$ indicates significant differences using Wilcoxon $U$ test, $N S$ indicates no significant difference.

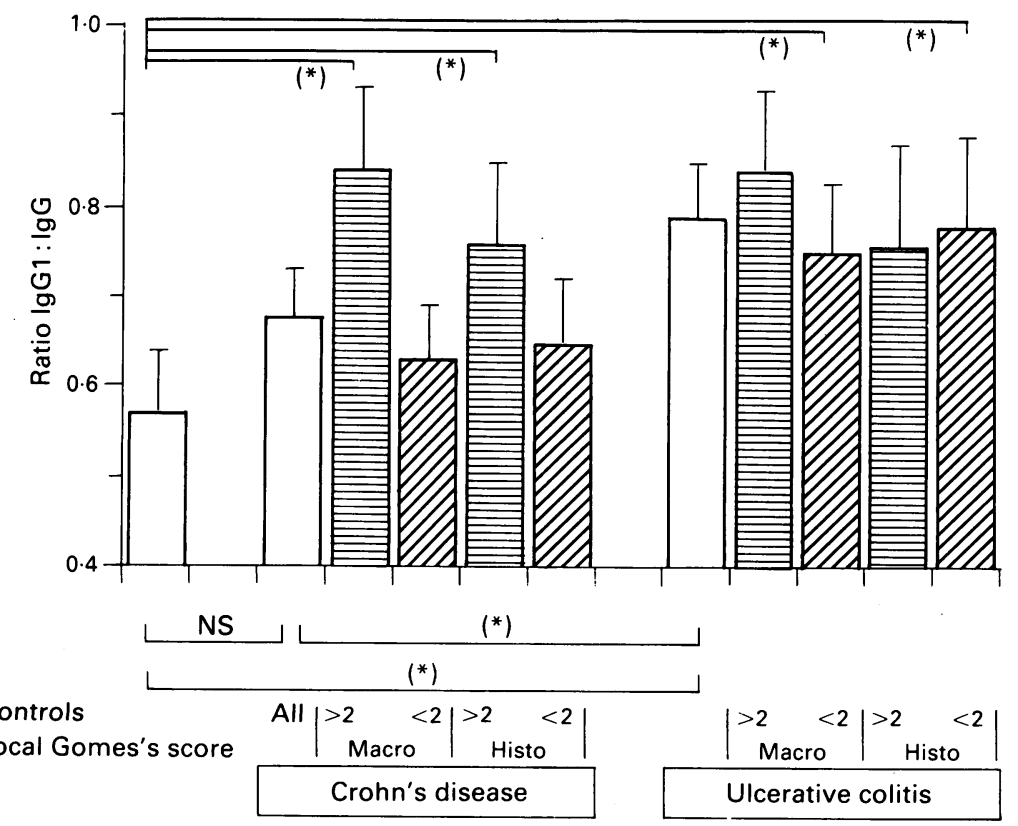
$v$ control subjects was raised, but just missed significance using Wilcoxon U test (Table III). In ulcerative colitis patients there was a significant difference between patients with mild disease and control subjects using macroscopic criteria (Table III). When histological criteria are used, we did not find significant differences, probably because of the small sample size.

IgGl/IgG RATIOS IN ULCERATIVE COLITIS, CROHN'S DISEASE, AND CONTROL SUBJECTS

The contribution of IgG1 to total IgG in subjects was quite variable in all groups and subgroups so that single ratios were not characteristic for one disease. However, mean IgG subclass ratios of disease groups were different from controls. The IgG1/IgG ratio was significantly different
TABLE III Wilcoxon $U$ test to determine significance of changes in $\operatorname{IgG}$ and IgGI production between controls and ulcerative colitis or Crohn's disease patients with minimal histological inflammation of the mucosa

\begin{tabular}{|c|c|c|}
\hline Group & Significance & $\begin{array}{l}\text { Median } \\
(n g / m l)\end{array}$ \\
\hline $\begin{array}{l}\text { Control }(n=12) \\
\text { CD local macroscopic index }<2(n=14)\end{array}$ & $\underset{\mathrm{p}=0.06 \mathrm{IgG}}{\mathrm{IgG}}$ & $\begin{array}{l}46 \\
24 \\
84\end{array}$ \\
\hline CD local histological index $<2(n=10)$ & $\begin{array}{l}\mathrm{p}=0.06 \mathrm{IgGl} \\
\mathrm{p}=0.08 \mathrm{IgG}\end{array}$ & $\begin{array}{r}44 \\
101\end{array}$ \\
\hline UC local macroscopic index $<2(n=15)$ & $\begin{array}{l}\mathrm{p}=0.08 \mathrm{IgGl} \\
\mathrm{p}<0.05 \mathrm{IgG}\end{array}$ & $\begin{array}{r}48 \\
123\end{array}$ \\
\hline UC local histological index $<2(n=8)$ & $\begin{array}{l}p<0.05 \text { IgGl } \\
p=0.30 \text { IgG } \\
p=0.25 \text { IgGl }\end{array}$ & $\begin{array}{l}121 \\
114 \\
104\end{array}$ \\
\hline
\end{tabular}

between ulcerative colitis patients and controls. This difference was also significant when ulcerative colitis patients with low inflammation and only slightly raised total IgG were compared. In contrast Crohn's disease patients showed an inflammation related increase in the proportion of IgG1. Thus, controls and all Crohn's disease patients did not have significantly different IgG1/IgG ratios. Only the subgroup of Crohn's disease patients with severe inflammation (local Gomes's index $>2$ ) produce significantly more IgGl, resulting in a significant change in the IgG1/IgG ratio (Wilcoxon U test, Fig 3).

COMPARISON OF IgG, IgG1, AND IgG2 PRODUCTION IN ULCERATIVE COLITIS AND CROHN'S DISEASE PATIENTS

In five control, 14 Crohn's disease, and 8 ulcerative colitis patients IMNC we could test IgG2 production in addition to that of IgG and IgG1. IgG2 could not be measured in all controls because it was below the detection limit of the assay used (standard curve from $10 \mathrm{ng}$ to $125 \mathrm{ng} / \mathrm{ml}$ ). Median IgG production was $115 \mathrm{ng} / \mathrm{ml}$ in ulcerative colitis and $106 \mathrm{ng} / \mathrm{ml}$ in Crohn's disease patients. Thus both groups showed similar degrees of inflammation. The proportion of IgG2 in total IgG was higher in Crohn's disease than ulcerative colitis patients, but this did not reach significance. As the IgGl/ IgG ratio in Crohn's disease patients with severe

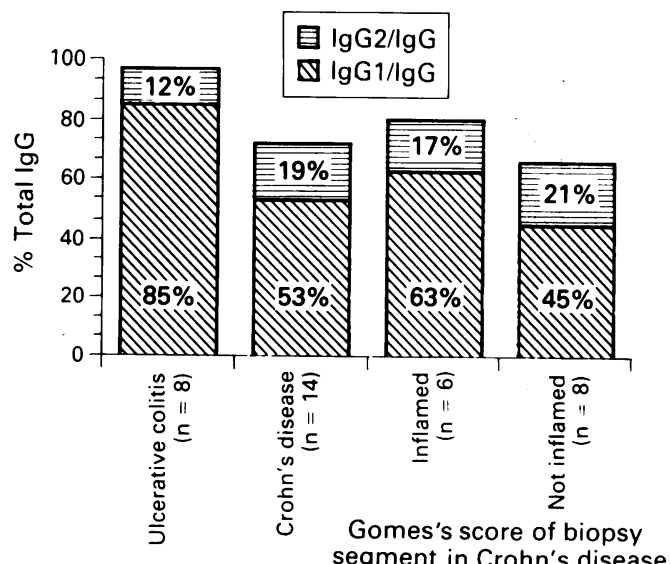

Figure 4: Percentage of immunoglobulin GI (IgGI) and IgG2 subclasses of total IgG in ulcerative colitis, Crohn's disease, and Crohn's disease subgroups. IgGI/IgG $\mathbb{N}$ and IgG1/IgG2 ratios (not shown) are significantly different between ulcerative colitis and Crohn's disease. IgG2/IgG 目 is not significantly changed between ulcerative colitis and Crohn's disease or Crohn's disease subgroups. 
inflammation was higher, we tested the possibility that Crohn's disease patients with low IgG concentrations might have significantly different IgG2 proportions compared with ulcerative colitis patients. We found a further increase in the IgG2/IgG ratio (Fig 4), but this was not significantly different from ulcerative colitis patients.

\section{Discussion}

We have established an isolation procedure for IMNC from biopsy specimens with cell yields high enough to perform functional studies. The use of biopsy specimens means that even inflammatory bowel disease patients who do not undergo surgery can participate in functional research of mucosal immunity.

It has been shown histologically by Soltoft, ${ }^{2}$ Brandtzaeg et $a l,{ }^{3}$ Baklien et $a l,,^{20}$ and several other groups, ${ }^{7821}$ that IgG positive immunocytes are increased in inflamed mucosa. Baklien et al showed that ileal mucosal inflammation and IgG immunocyte infiltration were correlated and that IgG immunocytes were not increased in slightly inflamed ileum of Crohn's disease patients. Kobayashi et al, ${ }^{22}$ however, found that IgG immunocytes were still increased in marginally inflamed mucosa from ulcerative colitis patients. Several studies examining inflammatory bowel disease as an entity ${ }^{722}$ found a correlation between inflammation and the number of IgG containing cells.

In functional studies, it was shown by Aiuti et al, ${ }^{23}$ MacDermott et al, ${ }^{24}$ Danis et al, ${ }^{25}, \mathrm{Wu}$ et $a l,{ }^{26}$ and Verspaget $e t a l,{ }^{9}$ that Crohn's disease and ulcerative colitis IMNC produce increased amounts of IgG. Since Crohn's disease or ulcerative colitis patients in these studies underwent surgery, it seems likely that they had severe inflammation of the mucosa.

The data obtained from healthy controls show that IgG production in vitro can be measured even in normal mucosa. In vitro IgG production of IMNC from biopsy specimens confirms previous results in ulcerative colitis and Crohn's disease mucosa and thus validates our biopsy method. Using this method to evaluate patients with differing degrees of inflammation, we showed that IgG and IgGl production is not correlated to subjective clinical indices and shows only loose correlation to acute phase parameters of the patients' sera. Yet IgG production in vitro and inflammation of the mucosa - measured endoscopically and histologically - correlate well in Crohn's disease and ulcerative colitis. These functional data supplement histological data from several groups and show that biopsy specimens are sufficient to measure IgG production of the mucosa at different disease stages, including remission. When Crohn's disease and ulcerative colitis patients with slight inflammation of the mucosa were compared with controls, we found increased median IgG and IgGl production in both diseases. Ulcerative colitis patients with a low macroscopic Gomes's score were significantly different from controls. Our data support the idea that increased IgG production is an early event in the inflammation of Crohn's disease and ulcerative colitis, and that this may contribute to inflammation by its proinflammatory potency.

IgG subclasses have been examined histologically by Kett $e t$ al ${ }^{11}$ and Iizuka. ${ }^{28}$ Kett $e t$ al describe significant differences between ulcerative colitis and Crohn's disease mucosa in terms of percentages of IgG1 and IgG2 positive immunocytes. They did not examine controls. lizuka reported that ulcerative colitis patients had increased numbers of all IgG subclass positive cells compared with controls. However, relative changes were only significant for IgGl subclass. Functional studies by Scott et $a l^{\prime \prime}$ showed IgG subclass shifting between controls, ulcerative colitis, and Crohn's disease patients. They found a significant increase in IgG and IgG1 subclass production in ulcerative colitis, but the percentages of IgG subclasses were not tested for significance.

Our data show that the percentage of IgGl is significantly increased in ulcerative colitis compared with controls and Crohn's disease patients. In ulcerative colitis, we also found an intrinsic shift in IgG subclasses towards IgGl at all stages of inflammation. The relative IgGl increase in ulcerative colitis is significant, even in patients with slight mucosal inflammation and marginally raised IgG and IgGl. Thus ulcerative colitis patients have a genetically or environmentally induced immunoregulation abnormality at all stages. In contrast, in Crohn's disease patients we found significantly increased proportions of IgG1 in severely inflamed mucosa only. As the IgGl percentages in ulcerative colitis patients with severe inflammation are also higher than in ulcerative colitis patients with less inflamed mucosa, we suggest that IgGl production is correlated to inflammation in all diseases of the gut.

Because IgG2 production could not be measured in controls (it was below the sensitivity of our assay) we could only compare Crohn's disease and ulcerative colitis patients. The percentage of IgG2 was increased in Crohn's disease compared with ulcerative colitis patients (19v $12 \%)$ but this difference was not significant. The percentage of IgG1 and IgG2 produced by IMNC in our study and percentage of IgG subclass immunocytes according to Kett $e t$ al ${ }^{10}$ are very similar, again showing that IgG subclass production and phenotype are correlated.

IgG antibodies in colonic mucosa are considered to be a 'second line' of defence when immune exclusion by $\operatorname{IgA}$ antibodies is not sufficient. ${ }^{\prime}$ However, IgG has proinflammatory properties that can lead to aggravation or perpetuation of immune reactions. In this respect it is of interest that IgGl is more effective in complement activation than IgG2. ${ }^{28}{ }^{29}$ In addition, IgGl and activated complement have been shown along the epithelium in ulcerative colitis. ${ }^{30}$ Thus it seems likely that IgG1 and complement may contribute to the epithelial damage in ulcerative colitis.

1 Brandtzaeg P, Halstensen TS, Kett K, Krajči P, Kvale D, Rognum TO, et al. Immunobiology and immunopathology of human gut mucosa: Humoral immunity and intraepithelial lymphocytes. Gastroenterology 1989; 97: 1562-84.

2 Soltoft J. Immunoglobulin-containing cells in normal jejunal mucosa and in ulcerative colitis and regional enteritis. Scand f Gastroenterol 1969; 4: 353-60.

3 Brandtzaeg P, Baklien K, Fausa O, Hoel PS. Immunohistochemical characterisation of local immunoglobulin formation in ulcerative colitis. Gastroenterology 1974; 66: 1123-36. 
4 Persson S, Danielsson D. Studies on Crohn's disease II: Immunoglobulin-containing cells in the terminal ileum. Acta Chir Scand 1973; 139: 735-8.

5 Baklien K, Brandtzaeg P. Immunohistochemical characterisation of local immunoglobulin formation in Crohn's disease of the ileum. Scand 7 Gastroenterol 1976; 11: 447-57.

6 Bookman MA, Bull DM. Characteristics of isolated intestinal mucosal lymphoid cells in inflammatory bowel disease. Gastroenterology 1979; 77: 503-10.

7 Keren DF, Appelman HD, Dobbins WO, Wells JJ, Whisenant B, Foley J, et al. Correlation of histologic evidence of disease activity with the presence of immunoglobulin-containing cells in the colon of patients with inflammatory bowel disease. Hum Pathol 1984; 15: 757-63.

8 Rosekrans PCM, Meijer CJLM, van der Wal Am, Cornelisse $\mathrm{CJ}$, Lindeman J. Immunoglobulin containing cells in inflammatory bowel disease of the colon: a morphometric and immunohistochemical study. Gut 1980; 21: 941-7.

9 Verspaget HW, Peña AS, Weterman IT, Lamers CBH. Disordered regulation of the in vitro immunoglobulin synthesis by intestinal mononuclear cells in Crohn's disease. Gut 1988; 29: 503-10.

10 Kett K, Rogum TO, Brandtzaeg P. Mucosal subclass distribution of immunoglobulin $G$ producing cells is different in ulcerative colitis and Crohn's disease of the colon. Gastroulcerative colitis and Crohn's

11 Scott MG, Nahm Mh, Macke K, Nash GS, Bertovich MJ, MacDermott RP. Spontaneous secretion of IgG subclasses by intestinal mononuclear cells: differences between ulcerative colitis, Crohn's disease and controls. Clin Exp Immunol 1986; 66: 209-15.

12 Best WR, Becktel JM, Singleton JW, Kern F. Development of a Crohn's disease activity index. Gastroenterology 1976; 70: 439-44.

13 Harvey RF, Bradshaw JM. A simple index of Crohn's disease activity. Lancet 1980; i: 514.

14 Gomes P, Du Boulay C, Smith CL, Holdstock G. Relationship between disease activity indices and colonoscopic findings in patients with $92-5$.

15 Lennard-Jones JE, Ritchie JK, Hilder W, Spicer CC. Assessment of severity in colitis: a preliminary study. Gut 1975; 16: 579-84.

16 Truelove SC, Witts LJ. Cortisone in ulcerative colitis. Final report on a therapeutic trial. BMF 1955; 2: 1041-8.

17 Andre C, Descos L, Landais P, Fermanian J. Assessment of appropriate laboratory measurements to supplement the Crohn's disease activity index. Gut 1981; 22: 571-4.
18 Zeitz M, Quinn TC, Graeff AS, James SP. Mucosal T cells provide helper function but do not proliferate when stimulated by specific antigen in lymphogranuloma venerum proctitis in non-human primates. Gastroenterology 1988; 94 353-66.

19 Jefferis R, Reimer C. Evaluation of monoclonal antibodies having specificity for human IgG subclasses: results of an IUIS/WHO collaborative study. Immunol Lett 1985; 10: 223-52.

20 Baklien K, Brandtzaeg P. Comparative mapping of the local distribution of immunoglobulin-containing cells in ulcerative colitis and Crohn's disease of the colon. Clin Exp Immuno 1975; 22: 197-209.

21 Scott BB, Goodall A, Stephenson P, Jenkins D. Rectal mucosal plasma cells in inflammatory bowel disease. Gut 1983; 24: 519-24.

22 Kobayashi K, Asakura H, Hamada Y, Hibi T, Watanabe M, Yoshida T, et al. T lymphocyte subpopulations and immunoglobulin containing cells in the colonic mucosa of ulcerative colitis; a morphometric and immunohistochemical study. f Clin Lab Immunol 1988; 25: 63-8.

23 Aiuti F, Garofalo JA. Rectal immunoglobulin synthesis in ulcerative colitis. N Englf Med 1972; 287: 1151 .

24 MacDermott RP, Beale MG, Alley CD, Nash GS, Bertovich MJ, Bragdon MJ. Synthesis and secretion of IgA, IgM and IgG by peripheral blood mononuclear cells in human disease states, by isolated intestinal mononuclear cells, and by human bone marrow cells from ribs. Ann NY Acad Sci 1983 409: 498-509.

25 Danis VA, Harries AD, Heatley RV. In vitro immunoglobulin secretion by normal human gastrointestinal tissues, and alterations in patients with inflammatory bowel disease. Clin Exp Immunol 1984; 56: 159-66.

26 Wu KC, Mahida YR, Priddle JD, Jewell DP. Immunoglobulin production by isolated intestinal mononuclear cells from patients with ulcerative colitis and Crohn's disease. Clin Exp Immunol 1989; 78: 37-41.

27 Iizuka $M$. IgG subclass-containing cells in the human large bowel of normal controls, non-IBD colitis and ulcerative colitis. Gastroenterol fpn 1990; 25: 24-31.

28 Shakib F, Stanworth DR. Human IgG subclasses in health and disease. Ric Clin Lab 1980; 10: 561-80.

29 Heiner DC. Significance of immunoglobulin G subclasses. $A m \mathcal{F}$ Med 1984; 76: 1-6.

30 Halstensen TS, Mollnes TE, Garred P, Fausa O, Brandtzaeg $P$. Epithelial deposition of immunoglobulin $\mathrm{Gl}$ and activated complement (C3b and terminal complement complex) in ulcerative colitis. Gastroenterology 1990; 98: 1264-71. 